\title{
As relações do projeto de produtos com a cadeia de suprimentos: um estudo de caso no setor de eletrodomésticos
}

\author{
Andrea Cristina dos Santos ${ }^{\text {a* }}$, Fernando Antonio Forcellini ${ }^{\mathrm{b}}$ \\ a*andreasantos@unb.br, UnB, Brasil \\ bforcellini@deps.ufsc.br, UFSC, Brasil
}

\begin{abstract}
Resumo
O objetivo deste trabalho é a investigação da cadeia de suprimentos como outra dimensão da engenharia simultânea no projeto de produtos. Com base na revisão da literatura, foram identificadas quatro dimensões de investigação de relacionamento do projeto de produtos com a cadeia de suprimentos: abordagem de processos de negócios, envolvimento de clientes no projeto de produtos, envolvimento dos fornecedores no projeto de produtos e modularização de produtos. Desenvolveu-se um estudo de caso de um elo da cadeia de suprimentos do setor de eletrodomésticos, com o propósito de investigar os relacionamentos da cadeia de suprimentos com o projeto de produtos. Ao final, são analisadas as implicações dos resultados da pesquisa para inserção da cadeia de suprimentos, como outra dimensão da engenharia simultânea, no projeto de produtos.
\end{abstract}

Palavras-chave

Projeto de produtos. Cadeia de suprimentos. PDP. SCM.

\section{Introdução}

A habilidade para projetar novos produtos, por meio de respostas tecnológicas ou por atendimento às tendências dos clientes, não é garantia de sobrevivência no mercado (RUNGTUSANATHAM; FORZA, 2005). Hoje, mais que no passado, os negócios dependem das relações estratégicas com seus clientes e fornecedores, com o propósito de criar valor ao produto em desenvolvimento e com o objetivo de manter ou melhorar o posicionamento da empresa no mercado (HANDFIELD; NICHOLS JUNIOR, 2002).

0 aumento da heterogeneidade do mercado, com diminuição do ciclo de vida dos produtos, tem forçado muitas empresas a competirem em vários domínios. Destaca-se a competição simultânea em três domínios: produto, processo e cadeia de suprimentos (FINE, 1999; FIXSON, 2005). Essas idéias são muito importantes conceitualmente, no entanto, segundo Rungtusanatham e Forza (2005) e Fixson (2005), pouco se sabe ou se divulga sobre como são tomadas as decisões que consideram esses três domínios.

A abordagem de engenharia simultânea entre produto e manufatura, nas décadas de 1980 e 1990, foi um diferencial competitivo para empresas, com a melhoria dos fluxos de informações, diminuição dos tempos e custos de desenvolvimento de produtos (CLAUSING, 1995). 0 reconhecimento da integração do projeto do produto com o processo de manufatura foi distinguido por vários conceitos como design for assembly, design for manufacture, design for operability e outros DfX (HUANG, 1996).

A cadeia de suprimentos pode ser acrescida como outra dimensão da engenharia simultânea, na busca em assegurar a vantagem competitiva das empresas. Entretanto, o tema de cadeia de suprimentos, similarmente ao que aconteceu com o projeto do processo, tende a ser tratado como algo posterior ao projeto do produto (FINE, 1999). 
0 objetivo desta pesquisa é o estudo da cadeia de suprimentos como outra dimensão da engenharia simultânea no projeto de produtos. A fundamentação teórica está alicerçada na estrutura conceitual apresentada em Handfield e Nichols Junior (2002), Lambert e Cooper (2000), Sturgeon (2001), Rozenfeld et al. (2006), Mikkola e Skjoett-Larsen (2003) e Fixson (2003). Com base nos conceitos apresentados por esses autores, foram definidas quatro dimensões de investigação de relacionamento do projeto de produtos com a cadeia de suprimentos: abordagem de processos de negócios, envolvimento de clientes no projeto de produtos, envolvimento dos fornecedores no projeto de produtos e modularização de produtos.

A primeira parte desta pesquisa trata da revisão da literatura sobre as relações do projeto do produto com a cadeia de suprimentos, a base conceitual entre o processo de desenvolvimento de produtos (PDP) e gerenciamento da cadeia de suprimentos (Supply Chain Management - SCM). Na segunda parte, descreve-se a metodologia adotada e, logo após, o estudo de caso sobre as relações do projeto de produtos com a cadeia de suprimentos. Finalmente, são apresentadas as conclusões e sugestões para trabalhos futuros.

\section{Relacionamentos do projeto de produtos com a cadeia de suprimentos}

Tradicionalmente, o conceito de cadeia de suprimentos se refere ao fluxo de transformação dos produtos, desde estágio de matéria-prima até a entrega ao usuário final, focando-se principalmente no fluxo de material. Devido ao aumento da importância dos fluxos de informações e financeiro, e à agregação de valor na cadeia de suprimentos, o conceito de cadeia de suprimentos que melhor retrata esta pesquisa é o conceito de gerenciamento da cadeia de suprimentos apresentado por Lambert (2004) e Handfield e Nichols Junior (2002).

0 gerenciamento da cadeia de suprimentos (SCM) se refere ao gerenciamento das relações entre as empresas, mediante seus processos de negócios, para criar um sistema de valor. Por meio desse sistema se buscam maximizar as potenciais sinergias, diminuir os desperdícios, aumentar a eficiência e a eficácia dos processos de negócios, com o objetivo de adicionar valor para os clientes e stakeholders, tornando a cadeia de suprimentos mais competitiva.

É importante esclarecer que o conceito de sistema de valor aqui utilizado é o defendido por Sturgeon (2001). 0 sistema de valor é a integração das cadeias de valores dos atores envolvidos na concepção, manufatura, entrega e descarte de produtos ao cliente final. Em suma, é a interação dos atores envolvidos nas fases do processo de desenvolvimento de produtos para coprodução de valor.

Handfield e Nichols Junior (2002) e Lambert e Cooper (2000) apresentam o desenvolvimento de produtos como um dos processos de negócios no gerenciamento da cadeia de suprimentos, conforme ilustrado na Figura 1.

Na Figura 1 é apresentada uma estrutura de cadeia de suprimentos simplificada. São ilustrados: os fluxos de informações, de produto e financeiros, os processos de negócio da cadeia de suprimentos e a diversidade de domínios conhecimentos, no sentido montante (rede de fornecedores) e no sentido jusante (rede de distribuidores) e, internamente, a organização (fornecedores internos).

Logo, com base na literatura, podem-se identificar quatro dimensões para avaliar o relacionamento entre o projeto de produtos e a cadeia de suprimentos: abordagem de processo de negócios, envolvimento dos clientes no PDP, envolvimento dos fornecedores no PDP e processo de desenvolvimento de produtos modulares.

\subsection{Processos de negócio do SCM}

As atividades nos processos de negócios do SCM são influenciadas por inúmeras variáveis: tipo de produto, fase do ciclo de vida comercial do produto, mudanças das necessidades dos clientes, lançamento de novas tecnologias, pressões de regulamentação, concorrentes no mercado, entre outras. Essas variam em função do tempo, logo, impõem-se mudanças nos objetivos e estratégias dos processos de negócios que compõem o SCM.

A evolução das abordagens para o PDP está relacionada com o desenvolvimento de novos sistemas de gerenciamento e engenharia nas empresas de manufatura, no decorrer do tempo (WOMACK; JONES; ROOS, 1992; STARK, 2006).

0 processo de desenvolvimento de produtos (PDP) como um processo de negócio na cadeia de suprimentos consiste em planejar, executar, e controlar as atividades na cadeia de suprimentos, de forma sustentável e competitiva (LAMBERT, 2004). Assim, o PDP se relaciona com clientes e fornecedores - internos e externos a uma empresa, por meio das atividades nos processos de negócios. 0 compartilhamento de informações e conhecimentos entre os envolvidos auxilia na criação de um sistema de valor com o objetivo de atender às diferentes necessidades ao longo do PDP (HANDFIELD; NICHOLS JUNIOR, 2002; LAMBERT, 2004). 


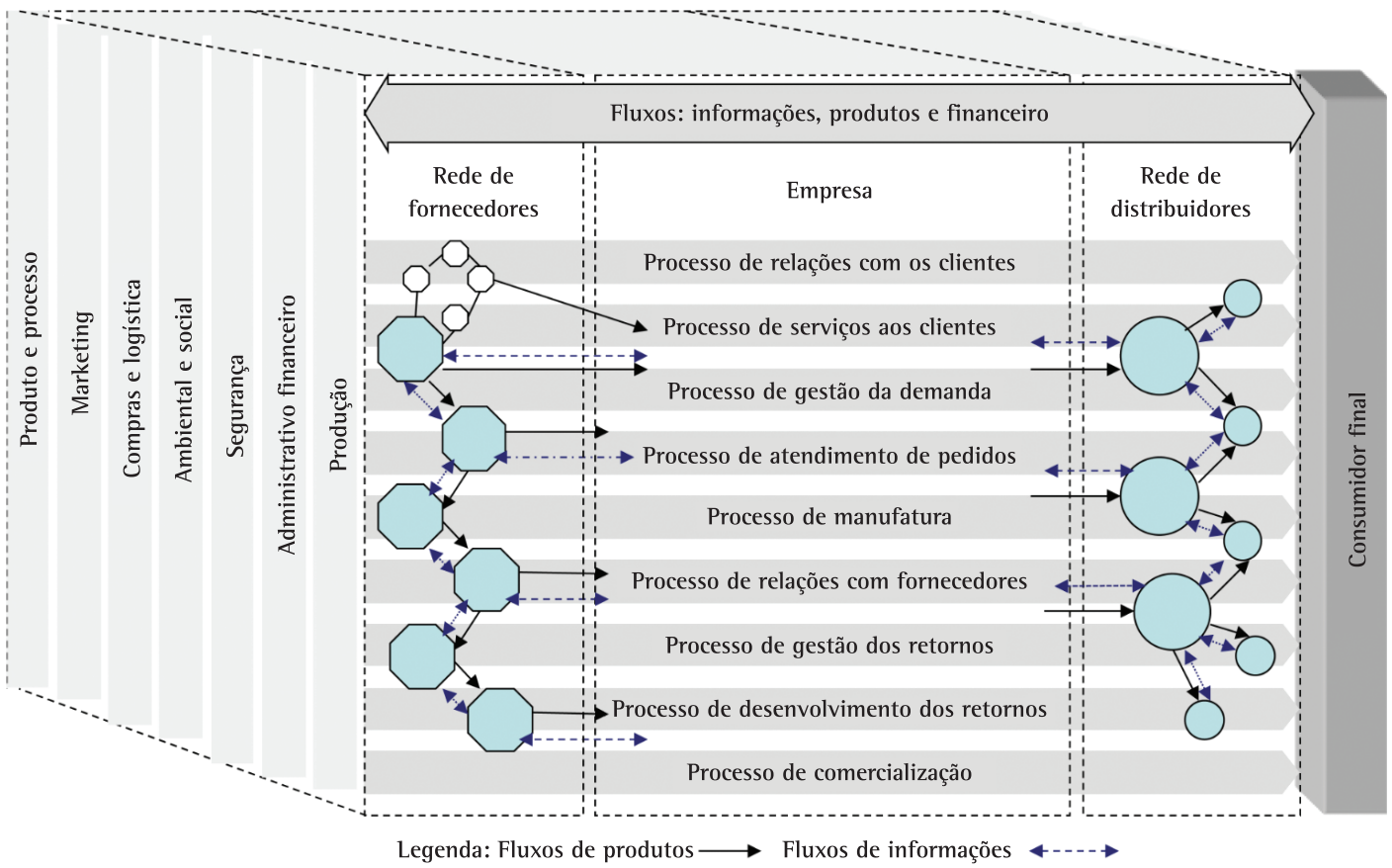

Figura 1. Modelo para o gerenciamento da cadeia de suprimentos. Fonte: adaptado de Handfield e Nichols Junior (2002) e Lambert e Cooper (2000).

Rozenfeld et al. (2006) propuseram um modelo de referência para o processo de desenvolvimento de produtos, apresentando as melhores práticas, métodos e ferramentas para o projeto do produto e para o projeto do processo. As principais contribuições encontradas no modelo de referência para o PDP, em relação à cadeia de suprimentos (e os trabalhos dos pesquisadores envolvidos na elaboração do modelo de referência para o PDP), são a indicação de algumas atividades em que pode haver o envolvimento dos fornecedores diretos. Os trabalhos de Santos e Forcellini (2005) e Santos, Forcellini e Kieckbusch (2006) mostram que os modelos de referências para o PDP podem auxiliar as empresas a visualizar "como e quando" os fornecedores poderão ser envolvidos no PDP.

Outros dois processos importantes no estudo das relações entre cadeia de suprimentos e o PDP são o de relacionamento com os clientes e o de relacionamento com o fornecedor.

\subsection{Processo de relacionamento com $o$ cliente}

Nas décadas de 60 e 70, os engenheiros de projeto de produto se focaram na tradução das necessidades dos clientes, em especificações de projeto do produto (HANDFIELD; NICHOLS JUNIOR, 2002). Desde então, tem sido publicado um grande número de artigos envolvendo os termos: customer focus; customer service; customer first; customer satisfaction; consumer for design; user-oriented design, human-centered design; customer-centric design e outros, discutindo diferentes pontos de vista sobre o envolvimento dos clientes no PDP (CLAUSING, 1995; HUANG, 1996; OTTO; WOOD, 2000; TSENG; PILLER, 2003; PAHL et al., 2005; LIU; WONG; LU, 2008).

Um aspecto comum entre os artigos é a necessidade de interações com os clientes no PDP, para execução de atividades de coleta e análise de necessidades dos clientes. 0 envolvimento do cliente pode ocorrer por meio de atividades de identificação de oportunidades, concepção do produto, testes, lançamento, compra, venda, uso, manutenção, transporte e descarte do produto (KLEEF; TRIJP; LUNING, 2005; STARK, 2006; MASCITELLI, 2006).

Os mecanismos empregados para interação com os clientes são desde técnicas tradicionais de pesquisas de marketing, visitas e reuniões dos consumidores com a equipe de desenvolvimento de produtos, técnicas de brainstorming a recursos mais sofisticados como fóruns de discussão na internet, kits de ferramentas que permitem ao usuário criar protótipos virtuais ou até mesmo a criação de novas funcionalidades (ALAM, 2002; LAGROSEN, 2005; NAMBISAN; BARON, 2009).

A abordagem utilizada para processo de relacionamento com o cliente considerada nesta 
pesquisa é a de coprodução de valor na cadeia de suprimentos, denominada por Lusch (2007) de Market(ing) with. 0 cliente é um parceiro que interage com a empresa e participa do processo de coprodução de valor.

Bonner (2010) demonstra, com base em um estudo realizado em 299 empresas, que a coprodução de valor durante o PDP ocorre por meio das relações de interatividade com os clientes em 3 dimensões: bidirecionalidade, participação e resolução de problemas em conjunto. A bidirecionalidade é considerada a tomada de decisão de cada uma das partes (cliente e empresa).

Os estudos sobre o envolvimento dos clientes no PDP não são novos, o que se destaca é a importância do tempo de atualização das informações repassadas ao PDP e a importância da interatividade com os clientes para a coprodução de valor durante o PDP.

\subsection{Processo de relacionamento com o fornecedor}

Nos últimos anos, uma grande quantidade de artigos foi publicada enfatizando os efeitos da participação do fornecedor no PDP, ao se relatarem as vantagens e desvantagens do envolvimento do fornecedor no PDP, enfocando principalmente a prática do early supplier involvement - ESI (envolvimento do fornecedor nas fases iniciais do PDP) como uma prática de vantagem competitiva nas empresas (BIROU; FAWCETT, 1994; BIDAULT; DEPRES; BUTLER, 1996; HOLMEN; KRISTESEN, 1998; WYNSTRA et al., 2001; CALVI; DAIN; BONOTTO, 2001). O ESI envolve o fornecedor no início do PDP e, assim, o fornecedor traz sua competência e know-how a serviço de um produto desenvolvido mais rapidamente a um custo menor e com qualidade melhor. Os fatores que têm levado muitos setores industriais a adotar a prática do ESI são explorados por Bidault, Depres e Butler (1996). Os autores dividem os fatores em 3 grupos principais: as pressões advindas do ambiente externo, as regras sociais e industriais vigentes e as opções da empresa. Mclvor, Humpreys e McAleer (1997) argumentam que a manutenção da competitividade pode ser dividida em objetivos estratégicos e operacionais, em objetivos de longo e curto prazo, respectivamente. As vantagens do envolvimento do fornecedor em curto prazo geralmente associam: melhoria da qualidade do produto, redução do custo do produto, redução do tempo de desenvolvimento de produtos e redução do custo total de desenvolvimento. As vantagens do envolvimento do fornecedor no PDP em curto prazo podem ainda ser divididas na eficiência e na efetividade do envolvimento do fornecedor no PDP.
A eficiência do envolvimento do fornecedor no PDP pode reduzir o custo e o tempo de desenvolvimento, como a introdução de mudanças nas fases iniciais do PDP, aumento da comunicação entre a empresa e o fornecedor, com a separação das tarefas de desenvolvimento e a separação em módulos e subsistemas. A efetividade do envolvimento do fornecedor no PDP está relacionada com a redução de custos do produto e o aumento do valor do produto para o cliente, tais como a utilização de práticas de projeto para manufatura, qualidade e confiabilidade dos componentes, materiais alternativos e possibilidades para padronização dos componentes. As principais vantagens do envolvimento do fornecedor em longo prazo estão geralmente associadas com: ser mais eficiente e eficaz em colaborações futuras; alinhamento das estratégias tecnológicas na cadeia de suprimentos; melhoria do acesso das tecnologias do fornecedor e contribuições para a diferenciação dos produtos.

0 alinhamento estratégico entre as parcerias é um dos pontos-chave do sucesso de integração do fornecedor no PDP (HSUAN, 1999). A estratégia de PDP deve estar em sincronia com as demais estratégias na cadeia de suprimentos. Baldwin e Clark (1997) apresentam a estratégia de modularização como possibilidade de aumentar a flexibilidade das empresas para se atender ao mercado. Os autores apresentam os fornecedores do setor automobilístico como especialistas para incorporarem inovações no produto final. Hsuan (1999) discute o efeito da modularização em projetos do tipo caixa-preta e os impactos das parcerias entre os clientes e os fornecedores. Os autores discutem a relação de parcerias versus grau de modularização. 0 alto grau de modularização é alcançado quando mais formas colaborativas de parcerias são lapidadas com os fornecedores. Mikkola e Skjoett-Larsen (2003) argumentam que a implementação da estratégia de outsourcing é possivel de se realizar somente quando um sistema pode ser decomposto tal que as interfaces dos componentes sejam bem especificadas e padronizadas. Esse é o foco central da estratégia de modularização de produtos. Além disso, o sucesso da estratégia de modularização não depende somente das habilidades e capacidades do fornecedor e da empresa para se conectarem por meio de suas interfaces, depende das mudanças tecnológicas que são introduzidas pelos outros participantes da cadeia de suprimentos (MIKKOLA; SKJOETT-LARSEN, 2003; STEPHAN; PFAFFMANN; SANCHEZ, 2008; LIU; WONG; LEE, 2008).

Outras necessidades da cadeia de suprimentos mencionadas na literatura como variedade de produtos, customização em massa e postergação da montagem (postponement) também são alcançadas com a 
implementação da estratégia de modularização de produtos. No entanto, na literatura, poucos trabalhos destacam a importância da implementação da estratégia de modularização como forma de promover o outsourcing na cadeia de suprimentos ou de envolver o fornecedor no processo de desenvolvimento de produtos. A maior parte dos artigos concentra-se em visualizar e caracterizar as parcerias em nível estratégico (SANTOS; FORCELLINI; KIECKBUSCH, 2007).

\subsection{Abordagem de modularização de produtos}

Abordagem de modularização dos produtos tem como principal objetivo o desenvolvimento de famílias de produtos ou plataformas de produtos (SIMPSON, 2004), ao mesmo tempo em que proporciona a possibilidade de maior variedade de produtos, o projeto simultâneo de várias partes e o projeto colaborativo (LIU; WONG; LEE, 2003; XU; LIANG, 2005; STEPHAN; PFAFFMANN; SANCHEZ, 2008).

0 relacionamento da modularização dos produtos com o SCM ocorre pelo relacionamento da estratégia de modularização de produtos com as outras estratégias da cadeia de suprimentos, como as de customização em massa (PINE 11, 1993; DURAY et al., 2000; DAHMUS; GONZALEZ-ZUGASTI; OTTO, 2000; TSENG; PILLER, 2003; KUMAR, 2004), plataforma de produtos (SANDERSON; UZUMERI, 1995; MEYER; LEHNERD, 1997; ERICSSON; ERIXON, 1999; BALDWIN; CLARK, 2000), e outsourcing (RO; LIKER; FIXSON, 2007). Os autores argumentam que os melhores resultados são alcançados pelo alinhamento dessas estratégias com a estratégia de modularização dos produtos.

A literatura lista uma série de vantagens relacionadas à modularização dos produtos: aumento da variedade de produtos, redução de custos, economia de escala, aumento na velocidade de lançamento de novos produtos, redução do tempo de projeto, distribuição de atividades na cadeia de suprimentos, melhoria no relacionamento entre fornecedores e parceiros na cadeia de suprimentos, maior facilidade na manutenção e reparo e reciclagem, melhor controle da incerteza da demanda (ERICSSON; ERIXON, 1999; SANCHEZ; COLLINS, 2001; HSUAN, 1999; DAHMUS; GONZALEZ-ZUGASTI; OTTO, 2001).

Tseng e Piller (2003) reconhecem que o desenvolvimento de uma família de produto, assim como o projeto para customização em massa, envolve o planejamento sistemático da modularidade e da padronização das famílias de produto. A modularidade fornece a flexibilidade para diferentes arranjos a fim de atender às diferentes necessidades dos clientes. A padronização nas famílias de produto fornece a possibilidade de reduzir os custos, no decorrer do ciclo de vida. Zamirowski e Otto (1999) descrevem 3 tipos de plataformas: modular, escala e de geração de produtos. A plataforma modular é desenvolvida para criar as variações do produto por meio da configuração dos módulos existentes (MEYER; LEHNERD, 1997). A plataforma em escala facilita a diferenciação de variantes com as mesmas funções, mas com capacidades diferentes (SIMPSON, 2004). A plataforma geracional influencia o desenvolvimento de gerações de produtos (MARTIN; ISHII, 2002).

Simpson (2004) menciona que uma família de produtos modulares é uma abordagem notória para 0 desenvolvimento de uma plataforma reconfigurável, a qual é facilmente modificável ou atualizada pela adição, subtração e substituição de módulos.

Ro, Liker e Fixson (2007) relatam que a modularidade tem um grande impacto no processo de outsourcing das empresas, uma vez que as decisões referentes ao desdobramento do produto e agrupamento das partes influenciaram nas decisões de repasse de atividades na cadeia de suprimentos, pensando na cadeia de suprimentos com um todo e nas fases do ciclo de vida do produto (do projeto ao descarte). A estratégia de modularização dos produtos auxilia na implementação da modularização da produção e na modularização da cadeia de suprimentos.

Para Sturgeon (2001), a empresa líder, responsável pelo projeto do produto, realiza o outsourcing em grande escala de sua manufatura, não tendo que carregar o capital fixo (administrativo, financeiro, e produção), permitindo focar seus recursos na inovação de produtos. Dessa forma, torna-se mais organizacional e geograficamente flexível para atender ao mercado. Sturgeon (2002) argumenta que a modularização da cadeia de suprimentos passa em algum momento pela estratégia de modularização de produtos, em que as partes do produto são distribuídas na cadeia de suprimentos, para serem projetadas, manufaturadas, produzidas, montadas e distribuídas, construindo assim uma rede de empresas sobre um produto, a partir do projeto.

No contexto de modularização da produção e modularização da cadeia de suprimentos, Asan, Polat e Serdar (2004) argumentam que os trabalhos de modularização da produção e modularização da cadeia de suprimentos assumem a preexistência de uma arquitetura de produto previamente concebida, sem descreverem as origens e a importância das decisões relacionadas à arquitetura do produto. Os autores relatam que a implementação do projeto de produto modular força o sistema inteiro (produção e a cadeia de suprimentos) para uma configuração modular. Entretanto, os trabalhos no contexto de PDP pouco 
exploram o processo de um projeto modular, com um enfoque nas relações na cadeia de suprimentos.

Fixson (2003) faz uma extensa exploração da literatura, cujo objetivo é auxiliar na compreensão das conexões do enfoque estratégico com o enfoque operacional relacionado à modularidade dos produtos. 0 autor apresenta três perspectivas de análise para a modularidade: sistema, processo de criação do produto e respectivo ciclo de vida, que se ilustram na Figura 2.

A perspectiva de sistema foca-se em como a modularidade é descrita. Ulrich (1995) define arquitetura do produto como o esquema em que as funções do produto são alocadas em componentes físicos. lsso envolve o desdobramento funcional do produto, o mapeamento dos elementos funcionais em componentes e as interfaces dos componentes. Dependendo da interdependência e compartilhamento das interfaces, a arquitetura de um produto pode variar de integral para modular. Em uma arquitetura de produto integral, as interfaces dos componentes são acopladas, mudanças em um componente não podem ser feitas sem gerar mudanças nos outros componentes. No lado oposto, tem-se a arquitetura modular. Geralmente, a escolha não é entre uma arquitetura modular e integral, mas como os elementos funcionais devem ser tratados, inseridos em um modo modular e integral. Outro aspecto importante é em relação às interfaces e à definição de sistemas abertos e fechados. A estratégia de interfaces abertas permite que outras empresas possam desenvolver componentes para a arquitetura do produto. Por outro lado, as interfaces fechadas são protegidas por direitos à propriedade.

A segunda perspectiva está relacionada a: quando e onde são feitas as decisões para se criar um produto

Perspectiva sistema

(Como a modularidade é descrita?)

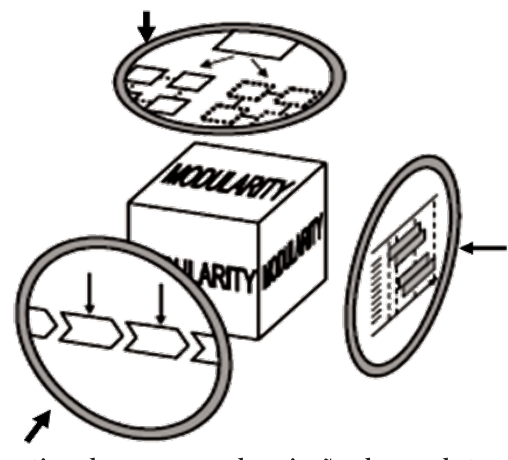

Perspectiva do processo de criação do produto

(Quando e onde a modularidade ocorre?)

Figura 2. Perspectivas da modularidade. Fonte: Fixson (2003, p. 75, tradução nossa). modular. Segundo Fixson (2003), os pontos de decisão sobre o processo de criação de modularidade do produto estão localizados no final da fase de pesquisa do mercado e no início da fase de projeto do produto. Os trabalhos nessa área focam-se no entendimento da necessidade da variedade de produtos para identificar peças comuns e padronizadas, com o objetivo de fazer o balanceamento entre os dois trade-offs. A terceira perspectiva está relacionada com os objetivos da modularidade no decorrer do ciclo de vida do produto e, para esta visão, diferentes caminhos são utilizados a fim de se descrever a modularidade, utilizando-se de outros DfX, além dos apresentados em Huang (1996).

Em sintese, a escolha da arquitetura do produto e de sua plataforma é influenciada pelas restrições tecnológicas (tanto do produto quanto do processo) e estratégias de negócio da empresa com seus fornecedores, na cadeia de suprimentos. Com base na revisão da literatura, foram identificados três elementos para integração da cadeia de suprimentos no PDP: arquitetura de produto, projeto da cadeia de suprimentos e projeto para cadeia de suprimentos. Esses elementos são básicos para implementação das estratégias de outsourcing, e modularização (SANTOS, 2008).

Em Sharifi, lsmail e Reid (2006), o projeto da cadeia de suprimentos compreende o entendimento das necessidades do mercado, o entendimento da situação atual da cadeia de suprimentos, a determinação dos atributos de desempenho da cadeia (com base nas análises dos requisitos dos clientes e situação atual da cadeia de suprimentos), o desdobramento dos atributos de desempenho para os processos, o planejamento do que a cadeia precisa ter em relação com a cadeia de suprimentos atual e o projeto e execução de todos os aspectos necessários para satisfazer os requisitos dos consumidores.

Logo, o projeto para cadeia de suprimentos significa desenvolver produtos que garantam e mantenham a sustentabilidade e competitividade da cadeia de suprimentos. Satisfazer somente as necessidades dos clientes, fornecendo o que eles desejam, não é suficiente. As empresas em uma cadeia de suprimentos devem ser capazes de entregar o produto certo, na hora certa, com os menores recursos envolvidos, sem sacrificar a qualidade ou serviço relacionado ao produto (HANDFIELD; NICHOLS JUNIOR, 2002). A partir da revisão da literatura, o projeto para cadeia de suprimentos pode ser considerado como o conjunto de princípios, incluindo o projeto para variedade, projeto para logística, projeto para postponement, projeto para manufatura, projeto para montagem e projeto para abastecimento (SANTOS, 2008). 
Entretanto, percebe-se que geralmente os modelos para desenvolvimento de produtos modulares (PAHL; BEITZ, 1996; PAHL et al., 2005; STONE; WOOD; CRAWFORD, 2000; DAHMUS; GONZALEZZUGASTI; OTTO, 2001; LIU; WONG; LEE, 2008) estão limitados aos aspectos técnicos e organizacionais internos, desconsiderando muitas vezes aspectos mais estratégicos. Isso influencia principalmente como as decisões de arquiteturas mais modulares ou mais integrais afetam o repasse de atividades a fornecedores.

\subsection{Níveis de relacionamento entre as abordagens de PDP e SCM}

Com base na revisão da literatura, identificaram-se relações diferentes entre as fases do PDP (ROZENFELD et al., 2006) e a coprodução de valor nos processos de relacionamento com clientes e fornecedores (STURGEON, 2001; LAMBERT, 2004). Identificaram-se ainda diferenças conceituais quanto à abordagem de SCM e PDP, como a de que, para alguns autores, o SCM começa suas atividades somente após o lançamento do produto no mercado. Supondo que esse cenário seria também encontrado em empresas, foram elaborados dois quadros sintetizando as diferentes abordagens da literatura.

0 Quadro 1 apresenta a identificação de seis níveis diferentes entre as possibilidades de envolvimento dos clientes nas fases do processo de desenvolvimento de produtos (ROZENFELD et al., 2006). Diferenças conceituais entre o PDP e o SCM: o SCM inicia após o lançamento de produtos ou em todas as fases do PDP. 0 processo de relacionamento com o cliente considera a abordagem de coprodução de valor nas fases do PDP (STURGEON, 2001; LUSCH, 2007) e interatividade (BONNER, 2010), ou a concentração de atividades na área funcional de marketing da empresa.

Nível 1 - A partir do lançamento do produto: o envolvimento do cliente no PDP ocorre somente nas fases de lançamento do produto no mercado e acompanhamento do produto no mercado. As relações com os clientes são realizadas pela área funcional de marketing, nas fases finais do PDP. O SCM inicia após o lançamento do produto no mercado. Essa abordagem é conhecida como to market(ing) (LUSCH, 2007), em que a interação com o cliente está restrita ao momento da compra.

Nível 2 - Definição do tipo de produto para o cliente: o envolvimento do cliente no PDP ocorre nas fases iniciais, sem haver uma preocupação com as estratégias da empresa (ou a empresa não desenvolve um planejamento estratégico para os produtos). Esse nível envolve a abordagem conhecida como market(ing) to (LUSCH, 2007), em que a geração de informação sobre os clientes ocorre, principalmente, mediante pesquisas surveys, grupos focais, observações de compra, entre outras técnicas de coleta de dados. A interatividade com o cliente é realizada pela área funcional de marketing, durante as fases iniciais e finais do PDP. O SCM começa após o lançamento do produto no mercado.

Nível 3 - Requisitos de projeto do produto: a organização define seus clientes, utiliza métodos estruturados para tratar as necessidades dos clientes como o QFD (quality function deployment), análise de valor para os clientes, FMEA (failure mode and effects analysis), nas fases de projeto do produto do PDP. A interatividade com o cliente é realizada pela área funcional de marketing, nas fases iniciais do PDP, inclui a abordagem market(ing) to (LUSCH, 2007), com o objetivo de identificar as necessidades dos clientes

Quadro 1. Níveis de envolvimento dos clientes nas fases do PDP e as relações com o SCM.

\begin{tabular}{|c|c|c|c|c|c|c|c|c|c|c|c|c|c|c|}
\hline & \multirow[b]{3}{*}{$\begin{array}{l}\text { Níveis de envolvimento } \\
\text { dos clientes }\end{array}$} & \multicolumn{9}{|c|}{ Fases do PDP } & \multicolumn{2}{|c|}{ Organização } & \multicolumn{2}{|c|}{ SCM } \\
\hline & & \multirow{2}{*}{ 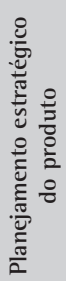 } & \multirow{2}{*}{ 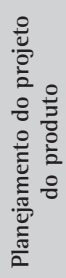 } & \multicolumn{5}{|c|}{ Desenvolver produto } & \multirow[b]{2}{*}{ 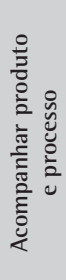 } & \multirow[b]{2}{*}{ 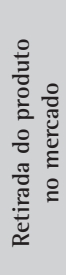 } & \multirow{2}{*}{ 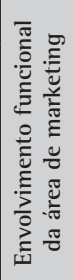 } & \multirow{2}{*}{ 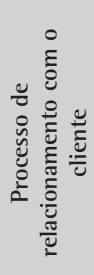 } & \multirow{2}{*}{ 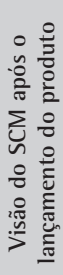 } & \multirow{2}{*}{ 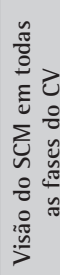 } \\
\hline & & & & 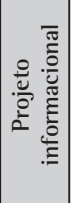 & 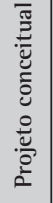 & $\begin{array}{l}\frac{0}{\pi} \\
\frac{\pi}{\pi} \\
\frac{\pi}{\pi} \\
\frac{\pi}{0} \\
\frac{0}{0} \\
\frac{0}{2} \\
\frac{0}{2}\end{array}$ & 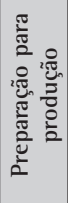 & 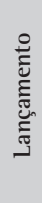 & & & & & & \\
\hline Nível 1 & A partir do lançamento do produto & & & & & & & & & & & & & \\
\hline Nível 2 & Definição do tipo de produto & & & & & & & & & & & & & \\
\hline Nível 3 & Requisitos de projeto do produto & & & & & & & & & & & & & \\
\hline Nível 4 & Visão estratégica do produto & & & & & & & & & & & & & \\
\hline Nível 5 & Visão por processos de negócios & & & & & & & & & & & & & \\
\hline Nível 6 & $\begin{array}{l}\text { Visão de processos de negócio na } \\
\text { cadeia de suprimentos }\end{array}$ & & & & & & & & & & & & & \\
\hline
\end{tabular}

Fonte: adaptado de Santos (2008). 
e resolver problemas de produtos existentes. Nas outras fases do PDP, a interatividade é bidirecional com caminho único (BONNER, 2010), ênfase na ferramenta de gerenciamento de relacionamento com o cliente. O SCM inicia após o lançamento do produto no mercado.

Nível 4 - Visão estratégica do produto: a organização alinha as estratégias de desenvolvimento de produtos com as necessidades dos clientes. 0 foco está na redução do tempo de desenvolvimento de produto. A interatividade com o cliente é realizada pela área funcional de marketing e inclui a abordagem market(ing) to (LUSCH, 2007), com o objetivo de identificar necessidades e resolver problemas de produtos existentes. Nessas fases do PDP, a interatividade é bidirecional com caminho duplo (BONNER, 2010). O SCM inicia após o lançamento do produto no mercado.

Nível 5 - Visão por processos de negócios: a organização alinha as estratégias de desenvolvimento de produtos com as necessidades dos clientes e realiza atualizações das necessidades dos clientes em todas as fases do PDP. A organização apresenta uma visão por processos de negócios para o processo de relacionamento com o cliente, entretanto, essa abordagem não está integrada com o PDP. 0 SCM inicia após o lançamento do produto no mercado. A dificuldade de integração do PDP e do SCM dificulta a coprodução de valor, e a implementação da abordagem market(ing) with (LUSCH, 2007), em que o cliente é considerado um parceiro que interage com a empresa e participa do processo de coprodução de valor.

Nível 6 - Visão por processos de negócios na cadeia de suprimentos: as empresas na cadeia de suprimentos alinham suas estratégias com as necessidades do cliente final, realizam atualizações constantes das necessidades dos clientes em todas as fases do PDP, podendo ser o cliente um membro da equipe de projeto para coprodução de valor, abordagem market(ing) with (LUSCH, 2007), tanto na resolução de problemas quanto na geração de funcionalidades para o novo produto, por meio de mecanismos que permitem alta interatividade da empresa e o cliente.

0 Quadro 2 apresenta a identificação de seis níveis diferentes entre as possibilidades de envolvimento dos fornecedores nas fases do processo de desenvolvimento de produtos (ROZENFELD et al., 2006). Diferenças conceituais entre o PDP e o SCM: o SCM inicia após o lançamento de produtos ou em todas as fases do PDP. 0 processo de relacionamento com o fornecedor considera a abordagem de coprodução de valor nas fases do PDP (STURGEON, 2001; SANTOS; FORCELLINI; KIECKBUSCH, 2007), a interatividade (PERKS, 2005; KOUFLEROS; VONDEREMBSE; JAYARAM, 2005; BONNER, 2010) ou concentração de atividades por meio da área funcional de compras da empresa (WYNSTRA; WEELE; WEGGEMAN, 2001).

Nivel 1 - Ajustes no desenvolvimento de produtos: o envolvimento do fornecedor nas fases PDP ocorre devido a alguma outra estratégia da empresa, que não está relacionada diretamente com a elaboração de estratégias para o desenvolvimento de produtos. Como consequência, as fases iniciais do PDP (projeto de produtos) têm que ser revistas. Por exemplo: fusões e aquisições de outras empresas, necessidade de ajustes nas especificações técnicas de produto, manutenção da produção, mudanças na legislação (SANTOS; FORCELLINI; KIECKBUSCH, 2007). As relações com os fornecedores são realizadas pela área funcional de compras. O SCM inicia após o lançamento do produto no mercado.

Quadro 2. Níveis de envolvimento dos fornecedores nas fases do PDP e as relações com o SCM.

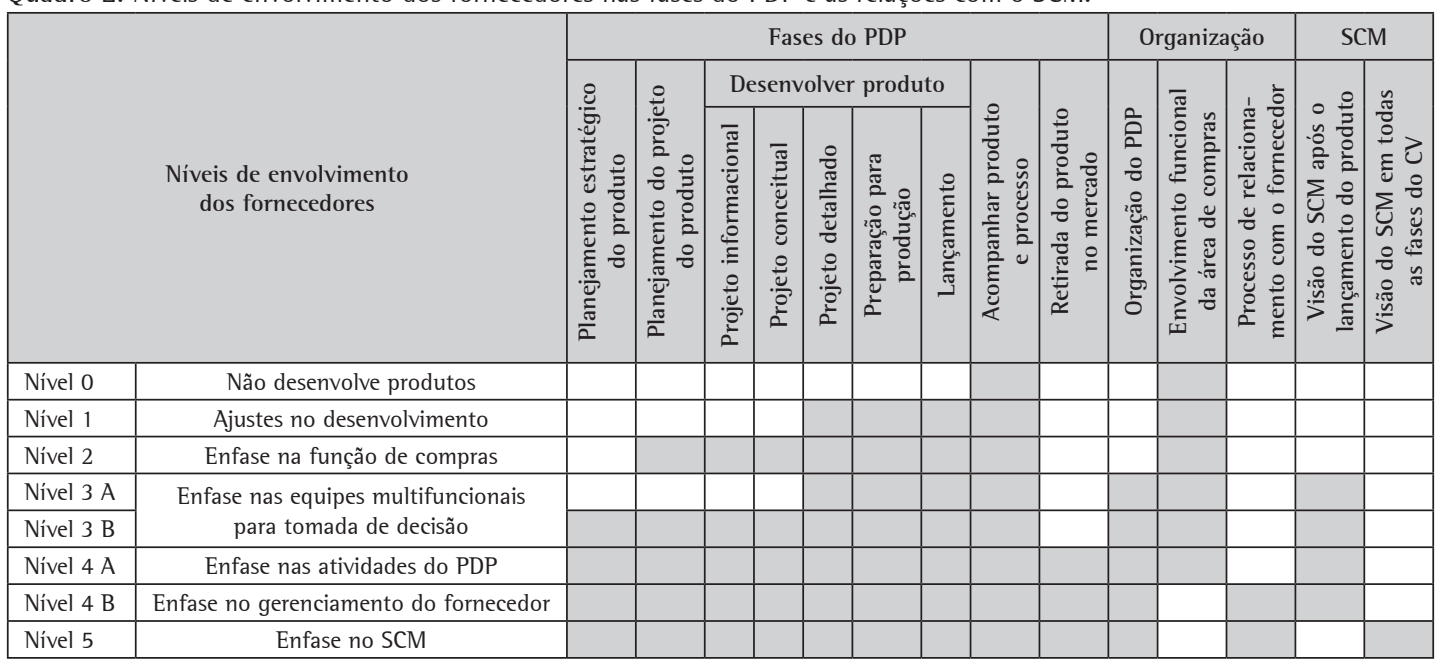

Fonte: adaptado de Santos (2008) 
Nível 2 - Ênfase na função de compras: os fornecedores são envolvidos no desenvolvimento de produtos, fases iniciais do PDP, devido à manutenção da competitividade da empresa por meio de objetivos operacionais em curto prazo, como: melhoria da qualidade do produto, redução do custo do produto, redução do tempo de desenvolvimento de produtos e redução do custo total de desenvolvimento (McIVOR; HUMPHREYS; McALEER, 1997). No entanto, não se faz nenhum significante grau de envolvimento do fornecedor no desenvolvimento de produtos. Como exemplos: compras de equipamentos e tecnologias fechadas; compras de produtos e peças padronizadas; compras de produtos catálogos; encomenda de projetos a partir das especificações para um fornecedor externo (SANTOS; FORCELLINI; KIECKBUSCH, 2007). A interatividade com o fornecedor é realizada pela área funcional de compras. 0 SCM inicia após a fase de lançamento do produto no mercado.

Nível 3 - Ênfase nas equipes multifuncionais para a tomada de decisão: este nível foi dividido em 3A e 3B. Subdivisão 3A: A empresa possui um processo de desenvolvimento de produtos sistematizado (fases, atividades e tarefas) (ROZENFELD et al., 2006). Os fornecedores são envolvidos nas fases iniciais do PDP devido à manutenção da competitividade da empresa, mediante objetivos operacionais em curto prazo: melhoria da qualidade do produto, redução de custo do produto, redução do tempo de desenvolvimento de produtos, redução do custo total de desenvolvimento. No entanto, apresenta pouco envolvimento dos fornecedores no processo de desenvolvimento de produtos (compras de equipamentos e tecnologias fechadas; compras de produtos e peças padronizadas; compra de produtos catálogos, encomenda de projetos a partir das especificações para um fornecedor externo) (SANTOS; FORCELLINI; KIECKBUSCH, 2007).

Subdivisão 3B: A empresa possui um processo de desenvolvimento de produtos sistematizado em fases, atividades e tarefas (ROZENFELD et al., 2006). Apresenta uma estratégia de desenvolvimento de produtos conservadora: ênfase na proteção tecnológica, controle dos projetos de produtos internamente, pouco envolvimento de fornecedores no PDP, compra de tecnologias abertas, parcerias por projetos (individuais) (SANTOS; FORCELLINI; KIECKBUSCH, 2007).

Nível 4A - Ênfase nas atividades do PDP: a empresa possui um processo de desenvolvimento de produtos sistematizado em fases, atividades e tarefas (ROZENFELD et al., 2006). Várias atividades desde o início do ciclo de vida do produto são delegadas aos fornecedores, adoção da prática de ESI (BIDAULT; DEPRES; BUTLER, 1996; McIVOR; HUMPHREYS; McALEER, 1997). O envolvimento do fornecedor no PDP está alicerçado em um processo de desenvolvimento de produto em que a empresa coordena e centraliza o projeto do novo produto, sabendo exatamente onde cada fornecedor está entrando (McIVOR; HUMPHREYS, 2004). 0 envolvimento do fornecedor no início do PDP ocorre quando há a necessidade. 0 grau de envolvimento do fornecedor no PDP depende da identificação das principais competências nas fases do ciclo de vida do produto - ocorre conforme as necessidades do projeto do produto. A interatividade (PERKS, 2005; KOUFLEROS; VONDEREMBSE; JAYARAM, 2005; BONNER, 2010) com o fornecedor depende da decisão no projeto de produto sobre arquitetura do produto (mais modular ou integral). Tendo por base a decisão no projeto de produto sobre a arquitetura, orienta as decisões de interação de comunicação com o fornecedor, baseada em estratégias de interação de curto e longo prazo no PDP (MIKKOLA; SKJOETT-LARSEN, 2003). Entretanto, o SCM se foca nas fases finais do PDP. As relações na cadeia de suprimentos são gerenciadas pela área funcional de compras ou suprimentos.

Nível 4B - Ênfase no gerenciamento do processo de relacionamento com os fornecedores. A diferença em relação ao nível anterior é referente ao gerenciamento das relações na cadeia de suprimentos. Neste nível, elas são realizadas por meio do processo de relacionamento com os fornecedores, abordagem de Lambert (2004).

Nível 5 - Ênfase no gerenciamento da cadeia de suprimentos: as empresas possuem PDP sistematizado (ROZENFELD et al., 2006). O PDP passa a ser visto como um processo distribuído e não como um processo centralizado, e envolve grande número de parceiros fora da corporação para juntos suprirem as necessidades dos consumidores. Envolvendo: equipes multifuncionais com representantes dos parceiros da cadeia de suprimentos; alinhamento das estratégias entre os principais parceiros da cadeia de suprimentos; desenvolvimento e implementação de indicadores comuns ao longo da cadeia de suprimentos (SANTOS, 2008).

\section{Metodologia}

0 escopo desta pesquisa, de cunho qualitativo, consiste na investigação das relações da cadeia de suprimentos no processo de desenvolvimento de produtos modulares, com o propósito de analisar a cadeia de suprimentos como outra dimensão da engenharia simultânea no projeto de produtos. Ainda que estudos internacionais tenham abordado essa temática, verifica-se a ausência de trabalhos no contexto brasileiro. 
Inicialmente, foram realizadas as pesquisas documentais ou bibliográficas. Para se descreverem os documentos, foi utilizada uma série de categorizações ou discriminações do conteúdo, eminentemente qualitativas. Verificaram-se a presença ou ausência de um determinado conteúdo e a intensidade e a forma com que ele é apresentado, fazendo-se as análises das relações da cadeia de suprimentos com o processo de desenvolvimento de produtos, sob perspectiva teórica, apresentado nos itens anteriores.

0 estudo de caso foi adotado como estratégia de investigação prática. Yin (2005) afirma que, embora os resultados de um estudo de caso não possam ser generalizados, devem possibilitar a disseminação do conhecimento a partir da compreensão e interpretação de fatos e fenômenos, normalmente isolados, de maneira mais profunda. 0 estudo de caso é a sequência lógica que conecta os dados empíricos à questão de pesquisa inicial do estudo e, em última análise, às suas conclusões.

Com o objetivo de garantir a qualidade e adequação das informações, foi definido o perfil da empresa para a pesquisa de campo (Quadro 3) e para garantir a confiabilidade dos dados coletados foram elaborados roteiros com questões semiabertas.

\section{Estudo de caso}

Para se decidir sobre a empresa-alvo do estudo de caso, foi elaborado um estudo prévio entre cinco empresas-membros de cadeia de suprimentos do setor eletrodoméstico, na região Sul do Brasil. A escolha final da empresa fundamentou-se no perfil desejado (Quadro 3) para pesquisa e a disposição da empresa em participar e, mesmo assim, com a pré-condição de não ser identificada.

A empresa $Y$ é uma divisão de uma grande fabricante mundial de eletrodomésticos que, na sua história recente, passou por modificações importantes na sua estrutura societária. Em meados da década de 1990, surgiu a empresa $Y$ oriunda da fusão de duas importantes marcas do mercado nacional de eletrodomésticos. Ainda na década de 1990, uma corporação americana, que já fazia parte da sociedade desde a década de 1950, assume o controle acionário da empresa, tendo ampliado sua participação nos últimos anos. A fonte de dados para o estudo foi um dos engenheiros responsáveis pela implementação da estratégia de modularidade, o qual se reporta para um escritório nos EUA.

A empresa anteriormente (antes de ser incorporada por uma grande multinacional) tinha como foco o projeto do produto dirigido pela tecnologia, abordada em Fixson (2005). Logo, para cada novo produto lançado no mercado, grandes esforços (recursos utilizados) eram feitos, principalmente nos principais componentes técnicos do produto que na maioria das vezes não eram percebidos pelos clientes. Esse período com foco em projetos de produtos mais integrados contribuiu para desenvolvimento do know-how, estando atual sua core competence no projeto do produto.

A empresa se encontra em um período de transição de produtos mais integrados para produtos mais modulares. Parte dessa estratégia deve-se ao crescimento do negócio projeto de produtos, o qual hoje é a core competence da empresa. Indo ao encontro de abordagens estratégicas para integrar o fornecedor no PDP apresentada em Mikkola e Skjoett-Larsen (2003).

No decorrer dos anos, a empresa realizou várias incorporações, comprando unidades de produção inteiras, espalhadas pelo mundo. Essas unidades de produção apresentam diferenças culturais e de competências, para as quais a empresa está buscando melhorar a governança interna. Devido à inserção da empresa na cadeia global, ela busca fornecer produtos mais customizados para os clientes, utilizando menos

Quadro 3. Perfil desejado.

\begin{tabular}{|c|l|}
\hline $\begin{array}{c}\text { Perfil } \\
\text { desejado }\end{array}$ & \multicolumn{1}{c|}{ Justificativas } \\
\hline Setores & $\begin{array}{l}\text { Procurou-se explorar outros setores fora do setor automobilístico. Existe um grande volume de trabalhos que se concentra no setor } \\
\text { automobilístico, enquanto outros setores, como o de eletrodomésticos, são menos explorados. Entretanto, uma empresa pode } \\
\text { fazer parte de mais de um setor: como telefonia, eletrodoméstico e automotivo, dependendo da posição na cadeia de suprimentos. }\end{array}$ \\
\hline Empresa & $\begin{array}{l}\text { 1. Lançamento de produtos no mercado com periodicidade regular. } \\
\text { 2. O lançamento de produtos é feito a partir do desenvolvimento interno da empresa de uma forma mais organizada (apresenta } \\
\text { o PDP estruturado). } \\
\text { 3. O produto a ser lançado é produzido em massa (para estoque) ou a empresa está buscando a customização em massa. } \\
\text { 4. O produto deve ser considerado benchmarking industrial pela comunidade industrial e acadêmica. }\end{array}$ \\
\hline Respondente Conheça as estratégias de desenvolvimento de produtos da empresa. \\
2. Tenha mais do que 5 anos de conhecimento sobre desenvolvimento de produtos. \\
3. Tenha conhecimento sobre as decisões de como é montado ou manufaturado o produto. \\
4. Exerça cargo de gerência (tomada de decisão). \\
5. Tenha conhecimento sobre o PDP e cadeia de suprimentos.
\end{tabular}

Fonte: elaborado pelos autores. 
recursos (customização em massa), sendo a estratégia de modularização dos produtos a partir do projeto exemplificada em Fixson (2005).

A empresa possui um escritório central de arquitetura do produto, localizado nos Estados Unidos, com o objetivo de fornecer as diretrizes e apoiar os mentores regionais no gerenciamento da arquitetura do produto, nas linhas de negócio da empresa, tendo como atividade principal definir os módulos do produto que serão globalizados, e quais módulos serão mantidos regionalmente. Dessa forma, mantendo-se inserida na estratégia de customização em massa. A visão de longo prazo da empresa é deixar de executar todas as fases do PDP e concentrar-se nas atividades projeto e vendas para os clientes. Essa estratégia é discutida em Tseng e Piller (2003) e Mikkola e Skjoett-Larsen (2003), em que um produto mais modular permite a flexibilidade para diferentes arranjos a fim de atender às diferentes necessidades dos clientes. Embora Fugita (2000) destaque a importância do projeto de interface para alcançar a variedade de produto na cadeia de suprimentos, percebeu-se que a empresa em estudo ainda permanecia na modularização com foco interno.

\subsection{O relacionamento com cliente e fornecedores na empresa $Y$}

A empresa hoje faz vendas on-line por meio de um site de acesso direto ao cliente, interatividade bidirecional com caminho duplo (BONNER, 2010). 0 relacionamento com o cliente também é feito pela manutenção dos produtos no mercado, e essa atividade é realizada por outras empresas (outsourcing). Mascitelli (2006) enfatiza a importância da coleta de informações pelas equipes de trabalho que estão no campo, em contato direto com o cliente. Stark (2006), no entanto, ressalta o risco de perdas de informações ao fazer o outsourcing dessas atividades. A empresa está implementando formulários eletrônicos, mediante dispositivos móveis com a finalidade de captar essas informações dos clientes.

Outros mecanismos de interação com os clientes citados na literatura (ALAM, 2002; LAGROSEN, 2005; NAMBISAN; BARON, 2009) são utilizados pela empresa: recebimento de e-mails e cartas com sugestões de novos produtos, grupos focais, teste de conceito, visitas e reuniões dos consumidores com a equipe de desenvolvimento de produto e observação de consumidores. Recursos mais sofisticados de envolvimento de consumidores no PDP não foram identificados durante a pesquisa.

A empresa $Y$ em relação aos clientes possui uma visão estratégica para o desenvolvimento de produto, ou seja, está no nível 4 do Quadro 1: a organização alinha as estratégias de desenvolvimento de produtos com as necessidades dos clientes. 0 foco está na redução do tempo de desenvolvimento de produto. A interatividade com o cliente é realizada pela área funcional de marketing, nas fases iniciais do PDP, inclui a abordagem market(ing) to (LUSCH, 2007), com o objetivo de identificar necessidades e resolver problemas de produtos existentes e, nessas fases do PDP, a interatividade é bidirecional com caminho duplo (BONNER, 2010). Entretanto, o SCM inicia após o lançamento do produto no mercado.

Em relação aos fornecedores, a empresa apresenta um nível menor de interação no PDP comparado com o envolvimento dos clientes no PDP. A empresa Y, em relação aos fornecedores, apresenta uma estratégia de envolvimento dos fornecedores conservadora: ênfase na proteção tecnológica, controle dos projetos de produtos internamente, pouco envolvimento de fornecedores no PDP, compra de tecnologias abertas, parcerias por projetos (individuais) (SANTOS; FORCELLINI; KIECKBUSCH, 2007), ou seja, encontra-se no nível 3B do Quadro 2.

Tomando como base os trabalhos de Bidault, Depress e Butler (1996) e Mclvor, Humphreys e McAleer (1997), pode-se dizer que a empresa, quando questionada sobre as principais motivações para envolvimento dos fornecedores e clientes no PDP, mencionou em ordem decrescente: sugestões de alternativas de materiais e componentes, redução dos custos dos produtos, redução do número de mudanças durante o projeto.

Os principais fatores listados para empresa, em relação à tomada de decisão sobre o envolvimento do fornecedor no PDP, com base nos fatores listados em Santos, Forcellini e Kieckbusch (2007), foram: as core competences dos fornecedores, atendimento às normas legais, avaliação de custos de produzir internamente ou repassar o projeto para fornecedor, custo do capital intelectual, confiabilidade do produto (módulo) entregue, a capabilidade do sistema logístico, incluindo a existência de plano de contingências, taxa de mudança tecnológica do fornecedor e o grau de risco e confiança do fornecedor.

Entre as principais dificuldades relatadas para a implementação do envolvimento do fornecedor no PDP estão as crenças e valores existentes na empresa, em geral não manifestadas formalmente, mas que direcionam as atividades na empresa. As crenças e valores existentes na empresa, assim como o envolvimento dos fornecedores, são tratados geralmente de acordo com a abordagem de outsourcing de atividades (SANTOS; FORCELLINI; KIECKBUSCH, 2007) e em conformidade com as perspectivas de gerenciamento dos relacionamentos e governança da cadeia de suprimentos. 


\subsection{O processo de modularização dos produtos na empresa $Y$}

A abordagem utilizada pela empresa na definição dos módulos é a de módulos funcionais (PAHL et al., 2005), ou seja, agrupamento de funções com o objetivo de atender às necessidades dos clientes $\mathrm{e}$ de retornos financeiros aos acionistas.

As interfaces dos módulos são detalhadas e isso permite que a empresa possa repassar para os fornecedores o projeto de subsistemas (módulos). Ou seja, pelo detalhamento das interfaces (especificações), a empresa repassa o projeto de um módulo a um fornecedor. No entanto, a empresa busca não comprar caixas-pretas, cujo conceito está apresentado em Calvi, Dain e Bonotto (2001). Procura comprar soluções que poderão ser modificadas futuramente. 0 repasse de projeto de módulos para os fornecedores ocorre na empresa quando a demanda de projetos não pode ser atendida pela equipe interna de projeto.

A empresa também vende projetos de módulos ou concepções de produtos para outros países e executa todas as fases do PDP, segundo abordagem apresentada em Rozenfeld et al. (2006) para o PDP. Assim, não existe na empresa, como literatura (SANDERSON; UZUMERI, 1995; MEYER; LEHNERD, 1997; ERICSSON; ERIXON, 1999; BALDWIN; CLARK; 2000), consenso do que seria uma plataforma de produtos.

A abordagem de desenvolvimento de produtos modulares está sendo implementada na empresa pela consultoria internacional, e empregada a metodologia abordada em Ericsson e Erixon (1999). Além disso, outras abordagens são também utilizadas no PDP da empresa Y, utilizando-se a perspectiva do ciclo de vida apresentada em Fixson (2005). Os DfX envolvidos são: projeto para manufatura e montagem, projeto para prototipagem, projeto para reciclagem de materiais, projeto para os serviços de manutenção, e também com foco na qualidade dos produtos: projeto para testabilidade de componentes eletrônicos e projeto seis sigma.

0 Quadro 4 sintetiza a intensidade das motivações para modularização dos produtos na empresa $Y$.

Os itens listados como muito forte e forte, no Quadro 4, vão ao encontro da estratégia de envolvimento do fornecedor em longo prazo, discutida em Mclvor e Humphreys (2004) e em Santos, Forcellini e Kieckbusch (2007).

A partir de questões semiestruturadas, listaram-se fatores críticos na implementação do processo de desenvolvimento de produtos modulares:

- Análise de valor agregado: geralmente essa análise inclui avaliações financeiras, valor para o cliente final, entretanto, outras análises como know-how e competências necessárias para agregar valor ao processo não são pontuadas;

- Análise de complexidade do produto: para analisar a complexidade do produto, a empresa utiliza-se de um software (sobre o qual não foram fornecidos maiores detalhes), contudo, foi relatado que os resultados obtidos ainda não são satisfatórios;

- As informações iniciais no road-map tecnológico, realizado durante a fase de planejamento estratégico do produto, no início do PDP, estão num nível de abstração elevado, provocando incertezas durante a definição dos futuros módulos.

Além desses fatores, foram listados objetivos conflitantes no processo de desenvolvimento de produtos modulares: necessidade de oferecer o maior número de variedades de produtos para satisfazer as necessidades dos clientes, por outro lado, a necessidade de reduzir a variedade de produtos por razões de custo e o esforço por uso de peças comuns ou padronizadas. Esses objetivos conflitantes são abordados por Ericsson e Erixon (1999), Sanchez e Collins (2001), Dahmus, Gonzalez-Zugasti e Otto (2001) e Mikkola (2003), como vantagens da estratégia de modularização dos produtos.

Quadro 4. Intensidade das motivações para implementação da modularidade na empresa Y.

\begin{tabular}{|c|c|c|c|c|c|c|}
\hline \multirow[b]{2}{*}{ Itens } & \multirow[b]{2}{*}{ Motivações para a modularidade } & \multicolumn{5}{|c|}{ Intensidade } \\
\hline & & $\begin{array}{l}\text { Muito } \\
\text { fraco }\end{array}$ & Fraco & Moderado & Forte & $\begin{array}{l}\text { Muito } \\
\text { forte }\end{array}$ \\
\hline 1.1 & Padronizar produtos e/ou subsistemas & & & & $x$ & \\
\hline 1.2 & Melhorar a montagem do produto & & & & $x$ & \\
\hline 1.3 & Postergar a montagem final do produto & & & & $x$ & \\
\hline 1.4 & Reduzir a variedade de produtos por razões de custos (estoque, por exemplo) & & & & & $x$ \\
\hline 1.5 & Melhorar as respostas às flutuações de demanda & & & & $\mathrm{x}$ & \\
\hline 1.6 & Diminuir o tempo de lançamento de novos produtos no mercado & & & & & $\mathrm{x}$ \\
\hline 1.7 & Atender os clientes por meio de customização em massa & & & & & $x$ \\
\hline 1.8 & Melhorar a qualidade dos produtos/serviços oferecidos para os clientes & & & $\mathrm{x}$ & & \\
\hline 1.9 & Facilitar modificações na geração de novos produtos & & & $\mathrm{x}$ & & \\
\hline 1.10 & Facilitar modificações no produto durante o ciclo de vida (do lançamento à retirada) & & & $\mathrm{x}$ & & \\
\hline 1.11 & Melhorar a introdução de novas tecnologias (P\&D) internos & & & & & $\mathrm{x}$ \\
\hline 1.12 & Melhorar o acesso aos conhecimentos tecnológicos externos & & & $\mathrm{x}$ & & \\
\hline
\end{tabular}


Uma das hipóteses sobre a dificuldade de perceber as vantagens da estratégia de modularização dos produtos deve-se à carência de consenso dos conceitos de modularização na empresa como um todo.

Percebeu-se que a empresa tem um processo de desenvolvimento de produtos estruturado e que estava no início da implementação de uma nova abordagem, processo de desenvolvimento de produtos modulares, este sendo tratado como um processo de negócio. No entanto, o mesmo não acontece com os processos de relacionamentos com clientes e fornecedores, já que apresentam uma abordagem funcional para 0 relacionamento com os clientes e com os fornecedores. Essa abordagem funcional reflete na forma como a empresa se relaciona com os clientes e com os fornecedores na cadeia de suprimentos.

\section{Considerações finais}

Para concluir, é necessário retomar o problema da pesquisa, a cadeia de suprimentos como outra dimensão da engenharia simultânea no projeto de produtos. A multidisciplinaridade de áreas envolvidas, para se obter a solução do problema da pesquisa, exigiu que a análise da literatura fosse alicerçada em uma estrutura conceitual apresentada por autores de diferentes áreas de conhecimento.

No referencial teórico, foi apresentado o PDP como um processo de negócio do SCM (LAMBERT; COOPER, 2000). Entretanto, Lambert e Cooper (2000) apresentam uma abordagem mais estratégica e ampla sobre os processos de negócio que compõem o SCM, sendo necessário um estudo mais aprofundado para proposição da solução do problema da pesquisa. Um dos pontos relevantes desta pesquisa foi o emprego do conceito de sistema de valor defendido por Sturgeon (2001). A abordagem defendida pelo autor é a interação das empresas por meio dos processos de negócio.

As contribuições do estado da arte são a apresentação de uma estrutura conceitual para fazer as relações da cadeia de suprimentos com o projeto de produtos. A inserção da cadeia de suprimentos como outra dimensão da engenharia simultânea no projeto de produtos é um desafio tanto para a academia quanto para as empresas. Ou seja, as equipes de projetos de produtos necessitam conhecer a cadeia de suprimentos do produto em desenvolvimento e considerar as informações da cadeia para a tomada de decisão durante as fases do PDP. Os resultados do estudo de caso na empresa $Y$ exemplificam algumas dessas necessidades. A relevância do estudo sobre o processo de desenvolvimento de produtos modulares justamente acontece porque os maiores impactos na cadeia de suprimentos são referentes às decisões relacionadas ao projeto da arquitetura do produto (ser mais ou menos modular, projeto de interfaces, subsistemas novos ou padronizados). Ainda que estudos internacionais tenham abordado essa temática, verifica-se ausência de trabalhos no contexto brasileiro.

Entretanto, conforme constatado no estudo de caso, a inserção da cadeia de suprimentos como outra dimensão da engenharia simultânea exige que a empresa consolide os conceitos internamente.

Uma limitação inicial refere-se à extensão dos resultados aqui encontrados. Tendo em vista as características da pesquisa, acredita-se que os resultados apresentados estabeleçam uma orientação para futuros estudos na área. 0 fato de a pesquisa ter sido realizada pela perspectiva do PDP, o SCM é constituído por outros processos de negócios (LAMBERT, 2004) e existe a oportunidade de exploração dos outros processos de negócios.

Este trabalho não encerra a investigação da cadeia de suprimentos como outra dimensão no projeto de produtos, mas, sim, apresenta uma solução, mediante abordagens de processos de negócios e modularização de produtos. Outras abordagens, como o estudo mais aprofundado do projeto para cadeia de suprimentos, projeto para logística (DfSC, DfL), são temas de trabalho futuro. 0 estudo aprofundado de níveis diferentes para o envolvimento dos clientes e fornecedores nas fases do PDP e as relações com o SCM podem ser usados como ponto de partida para construção de um modelo de maturidade.

Ressalta-se ainda que, embora estudos internacionais tenham abordado os temas aqui relatados, reafirmam-se a oportunidade e a importância de trabalhos no contexto brasileiro, envolvendo outros setores, além do automobilístico.

\section{Referências}

ALAM, I. An explory investigation of user involvment in new service development. Journal of the Academy of Marketing Science, v. 30, n. 3, p. 250-261, 2002.

ASAN, U.; POLAT, S.; SERDAR; S. An integrated method for designing modular products. Journal of Manufacturing Technology Management, v. 15, n. 1, p. 29-49, 2004. http://dx.doi.org/10.1108/09576060410512257

BALDWIN, C. Y.; CLARK, K. B. Managing in age of modularity. Harvard Business Review, v. 5, n. 5, p. 84-93, 1997.

BALDWIN, C. Y.; CLARK, K. B. The power of modularity. Massachusetts: MIT Press, 2000. 483 p.

BIDAULT, F. C.; DEPRES, C.; BUTLER, C. New product development an early supplier involvement (ESI): the drivers o ESI adoption. In: PRODUCT DEVELOPMENT MANAGEMENT ASSOCIATION INTERNATIONAL CONFERENCE, 1996, Orlando. Proceedings... Orlando, 1996. p. 2-21.

BIROU, L.; FAWCETT, S. E. Supplier involvement in integrating product development a comparisons of US and European Practices. International Journal of Physical Distribution \& Logistic Management, v. 24, n. 5, p. 4-14, 1994. http:// dx.doi.org/10.1108/09600039410063982

BONNER, J. Customer interactivity on new product performance: moderating effects of product newness and product embededness. Industrial marketing management, v. 39, 
n. 3, p. 485-492, 2010. http://dx.doi.org/10.1016/j. indmarman.2008.11.006

CALVI, R.; DAIN, M. A.; BONOTTO, M. V. How to manage early supplier involvement (ESI) into the new product development process (NPDP) - several lessons from a French study. In: INTERNATIONAL ANNUAL ISPERA CONFERENCE, 10., 2001, Jonkoping, Suécia. Proceedings... 2001. p. 153-160.

CLAUSING, D. Total quality development: a step-by-step, guide to word class concurrent engineering. New York: ASME Press, 1995. $506 \mathrm{p}$.

DAHMUS, J. B.; GONZALEZ-ZUGASTI, J. P.; OTTO, K. N. Modular Product Architecture. Design Studies, v. 22, n. 5, p. 409-424, 2001. http://dx.doi.org/10.1016/S0142694X(01)00004-7

DAHMUS, J. B.; GONZALEZ-ZUGASTI, J. P.; OTTO, K. N. Modular Product Architecture. In: ASME DESIGN ENGINEERING TECHNICAL CONFERENCES AND COMPUTERS AND INFORMATION IN ENGINEERING CONFERENCE, 2000, Baltimore. Proceedings... Baltimore: ASME, 2000. 11 p.

DURAY, R. et al. Approaches to mass customization: configuration and empirical validation. Journal of Operations Management, v. 18, n. 6, p. 605-625, 2000. http://dx.doi.org/10.1016/S0272-6963(00)00043-7

ERICSSON, A.; ERIXON, G. Controlling design variants: modular product platforms. Dearborn: Society of Manufacturing Engineers, 1999. $145 \mathrm{p}$.

FINE, C. Mercados em evolução contínua: conquistando vantagem competitiva num mundo em constante mutação. Tradução para o português de Afonso Celso da Cunha Serra. Rio de Janeiro: Campus, 1999. 262 p.

FIXSON, S. K. Product archicture assessment: a tool to link product, process, and supply chain design decisions. Journal of Operations Management , v. 23, n. 3, p. 345-369, 2005. http://dx.doi.org/10.1016/j.jom.2004.08.006

FIXSON, S. The multiple faces of modularity - a literature analysis of a product concept for assembled hardware products. Michigan: University of Michigan, Industrial and Operations Engineering, 2003. Disponível em: <http://www-personal. umich.edu/ fixson/U-M\%2010E\%20TR\%2003-05.pdf>. Acesso em: 15 mar. 2005.

FUGITA, K. Product Variety Optmization under Modular Architecture. In: INTERNATIONAL SYMPOSION ON TOOLS AND METHODS OF COMPETITIVE ENGINEERING - TMCE, 3., 2000, Netherlands. Proceedings... Netherlands: Delf, 2000. p. 451-464. Disponível em: <http://syd.mech.eng.osaka-u. ac.jp/papers/indexBefore2000-eng.html>. Acesso em: 15 abr. 2007.

HANDFIELD, R. B.; NICHOLS JUNIOR, E. Supply chain redesign: transforming supply chain into integrated value systems. Upper Saddle River: Prentice Halls, 2002, 371 p.

HOLMEN, E.; KRISTESEN, P. S. Supplier roles in product development: interaction versus portioning. European Journal of Purchasing \& Supply Management, v. 4, n. 1, p.185193, 1998. http://dx.doi.org/10.1016/S0969-7012(97)000233

HSUAN, J. Impacts of supplier-buyer relationship on modularization in new product development. European Journal of purchasing and Supply Management, v. 5, n. 3, p. 197-209, 1999. http://dx.doi.org/10.1016/S09697012(99)00026-X

HUANG, C. Q. Design for $X$ : concurrent engineering imperatives. London: Chapman \& Hall, 1996, 508 p.

KLEEF, E.; TRIJP, H. C. M.; LUNING, P. Consumer research in the early stages of new product development a critical review of methods and techniques. Food Quality and Preference, v. 16 , n. 3, p. 181-201, 2005. http://dx.doi.org/10.1016/j. foodqual.2004.05.012

KOUFLEROS, X.; VONDEREMBSE, M.; JAYARAM, J. Internal and external integration for product development: the contingency effects of incertainty, equivocality, and plataform strategy. Decision Science, v. 36, n. 1, p. 97-132, 2005. http://dx.doi.org/10.1111/j.15405915.2005.00067.x

KUMAR, A. Massa Customization: metrics and modularity. International Journal of Flexible Manufacturing Systems, v. 16 , n. 4 , p. 287-311, 2004. http://dx.doi.org/10.1007/ s10696-005-5169-3

LAGROSEN, S. Customer involvement in new product development: a relationship marketing perpective. European Journal of Innovation Management, v. 8, n. 4, p. 424436, 2005. http://dx.doi.org/10.1108/14601060510627803

LAMBERT, D. M. Supply chain management: processes, partnerships, performance. Second Edition. Sarasota: Hartley Press, 2004. 344 p.

LAMBERT, D. M.; COOPER, M. C. Issues in supply chain management. Industrial Marketing Management, v. 29, n. 1 , p. 65-83, 2000. http://dx.doi.org/10.1016/S00198501(99)00113-3

LIU, Z.; WONG, Y. S.; LEE, K. S. Integrated approach to modularize the conceptual product family architecture. International Journal of Advanced Manufacturing Technology, v. 26, p. 83-96, 2008.

LUSCH, R. F. Marketing envolving identify: defining our future. American Marketing Association, v. 26, n. 2, 2007.

MARTIN, M. V.; ISHII, K. Design for variety: developing standardized and modularized product platform architectures. Research in Engineering Design, v. 13, n. 4, p. 213-235, 2002.

MASCITELLI, R. The lean product development guide book: everything your design team needs to improve efficient and slash time to market. Technology perspectives, 2006. $310 \mathrm{p}$.

MASCITELLI, R. The lean product development guide book: everything your design team needs to improve efficing and slash time to market. Technology perspectives, 2006. 310 p.

McIVOR, R. T.; HUMPHREYS, P. K. Early supplier involvement in the design process: lessons from the electronics industry. Omega, v. 32, n. 3, p. 179-1999, 2004. http://dx.doi. org/10.1016/j.omega.2003.09.005

McIVOR, R. T.; HUMPHREYS, P. K.; McALEER, W. E. A strategic model for the formulation of an effective make or buy decision. Management Decision, v. 35, n. 2, p. 169178, 1997. http://dx.doi.org/10.1108/00251749710160331

MEYER, M. H.; LEHNERD, A. P. Power of product development platforms: building value and cost leadership. New York: Free Press, 1997. 267 p.

MIKKOLA, J. H. Managing modularity of product archictures: toward an integrated theory. IEEE Transactions on Engineering Management, v. 50, n. 2, p. 204-218, 2003. http://dx.doi.org/10.1109/TEM.2003.810826

MIKKOLA, J. H.; SKJOETT-LARSEN, T. Early supplier involvement: implications for new product development outsourcing and supplier-buyer interdependence. Global Journal of Flexible Systems Management, v. 4, n. 4, p. 31-41, 2003.

NAMBISAN, S.; BARON, R. Virtual customer environments: testing a model of voluntary participation in value co-creation activities. Journal of Product Innovation Management, v. 26, n. 4, p. 388-406, 2009. http://dx.doi. org/10.1111/j.1540-5885.2009.00667.x

OTTO, K. N.; WOOD, K. L. Product design: techniques in reverse engineering and new product development. Upper Saddle River: Prentice Hall, 2000. 1071 p.

PAHL, G.; BEITZ, W. Engineering design: a systematic approach. 2. ed. Tradução para o inglês de Ken Wallace; Luciënne Blessing; Frank Bauert. London: Springer, 1996. 544 p.

PAHL, G. et al. Projeto na engenharia: fundamentos do desenvolvimento eficaz de produtos, métodos e aplicações. 6. ed. Tradução para português de Hans 
Andreas, revisão de Nazem Nacimento Wener. São Paulo: Edgard Blucher, 2005. 412 p.

PERKS, H. Specifying and Synchronizing partner activities in the dispersed product development process. Industrial Marketing Management, v. 24, n. 4, p. 85-95, 2005. http:// dx.doi.org/10.1016/j.indmarman.2004.08.002

PINE 11, B. J. Personalizando produtos e serviços: customização maciça a nova fronteira da competição dos negócios. Tradução para o português de Edna Emi Onoe Veiga. São Paulo: Makron Books, 1993. 334 p.

RO, Y. K.; LIKER, J. K.; FIXSON, S. Modularity as a strategy for supply chain coordination: the case of U.S auto. IEEE Transactions on Engineering Management, v. 54, n. 1, p. 172-189, 2007. http://dx.doi.org/10.1109/ TEM.2006.889075

ROZENFELD, H. et al. Gestão de desenvolvimento de produto: uma referência a melhoria do processo. São Paulo: Saraiva, 2006. $542 \mathrm{p}$.

RUNGTUSANATHAM, M.; FORZA, C. Coordinating product design, process desing, and supply chain design decisions. Part A: topic motivation, performance implications, and article review process. Journal of Operations Management, v. 23, n. 3, p. 319-324, 2005.

SANCHEZ, R.; COLLINS, R. P. Competing and learning in modular markets. Long Range Planning, v. 34, n. 6, p. 645-667, 2001. http://dx.doi.org/10.1016/S0024-6301(01)00099-1

SANDERSON, S.; UZUMERI, M. Managing product families: the case of the sony walkman. Research Policy, v. 24, n. 5, p. 761-782, 1995. http://dx.doi.org/10.1016/00487333(94)00797-B

SANTOS, A. C. Modelo de referência para o processo de desenvolvimento de produtos em Ambiente de SCM. 2008. 408 f. Tese (Doutorado em Engenharia Mecânica)-Universidade Federal de Santa Catarina, Florianópolis, 2008.

SANTOS, A. C.; FORCELlINI, F. A. A assessment of supplier involvement in the product development process (PDP) based on a reference model for food industry. Product Management \& Development, n. 1, v. 3, p. 49-53, 2005.

SANTOS, A. C., FORCELLINI, F. A.; KIECKBUSCH, R. E. Involvement assessment of supplier in the product development process (PDP) for ceramic tile industry. In: INTERNATIONAL CONFERENCE ON PRODUCTION RESEARCH - ICPR AMERICAS, 2006, Curitiba. Anais... Curitiba: Produtrônica, 2006.

SANTOS, A. C.; FORCELLINI, F. A.; KIECKBUSCH, R. E. Linking outsourcing process and product development process: literature analysis. Product Management \& Development, n. 2, v. 5, p. 111-126, 2007.

SHARIFI, H.; ISMAIL, H.; REID, l. Achieving agility in supply chain through simultaneous design of and design for supply chain. Journal of Manufacturing Technology
Management, v. 17, n. 8, p. 1078-1098, 2006. http://dx.doi. org/10.1108/17410380610707393

SIMPSON, T. W. Product Platform Desing: method and aplication. Artificial Intelligence for Engineering Design, Analysis and Manufacturing, v. 18, n. 1, p. 3-20, 2004.

STARK, J. Product lifecycle management: 21st century paradigm for product realization. London: Springer, 2006. $411 \mathrm{p}$.

STEPHAN, M.; PFAFFMANN, E.; SANCHEZ, R. Modularity in cooperative product development: the case of MCC 'smart' Car. International Journal of Technology Management, v. 42, n. 4, p. 439-458, 2008. http://dx.doi.org/10.1504/ IJTM.2008.019385

STONE, R.; WOOD, K.; CRAWFORD, R. A Heuristic Method for Identifying Modules for Product Architectures. Design Studies, v. 21, n. 1, p. 5-31, 2000. http://dx.doi.org/10.1016/ S0142-694X(99)00003-4

STURGEON, T. J. Modular production networks. A new American Model of Industrial Organization. Industrial and Corporate Change. Industrial and Corporate Change, v. 11, n. 3, p. 451-496, 2002. http://dx.doi.org/10.1093/icc/11.3.451

STURGEON, T. J. How to we define value chains and production networks. IDS Bulletin, v. 32, n. 3, p. 1-10, 2001. http:// dx.doi.org/10.1111/j.1759-5436.2001.mp32003002.x

TSENG, M. M.; PILLER, F. T. The customer centric enterprise: advances in mass customization and personalization. Berlin: Springer, 2003. $535 \mathrm{p}$.

ULRICH, K. T. The role of product architecture in the manufacturing firm. Research Policy, v. 24, n. 3, p. 419- 440, 1995. http://dx.doi.org/10.1016/00487333(94)00775-3

WOMACK, J. P.; JONES, D. T.; ROOS, D. A máquina que mudou o mundo. 12. ed. Tradução para o português de lvo Korytwki. Rio de Janeiro: Campus, 1992. 347 p.

WYNSTRA, F.; WEELE, A.; WEGGEMAN, M. Managing supplier involvement in product development: three critical issues. European Management Journal, v. 19, n. 2, p. 157-167, 2001. http://dx.doi.org/10.1016/S02632373(00)00090-6

$\mathrm{XU}$, Z. H.; LIANG, M. Concurrent optimization of product module selection and Assembly line Configuration: a multiobjective approach. Journal of Manufacturing Science and Engineering-Transactions of Technology Management, v. 42, n. 4, p. 439-458, 2005.

YIN, R. K. Estudo de caso: planejamento e métodos. 3. ed. Tradução de Daniel Grassi. Porto Alegre: Bookman, 2005.

ZAMIROWSKI, E. J.; OTTO, K. N. ldentifying product portfolio architecture modularity using function and variety heuristic. In: INTERNATIONAL CONFERENCE ON DESIGN THEORY AND METHODOLOGY - DESIGN ENGINEERING TECHNICAL CONFERENCES, 11., 1999, Las Vegas, Nevada, USA. Proceedings... ASME, 1999. $11 \mathrm{p}$.

\title{
The relations between product design and supply chain: a case study in the home appliance sector
}

\begin{abstract}
This paper seeks to investigate the supply chain as another dimension of concurrent engineering in product design. Based on the literature review, four dimensions of investigation of relationship between product design and supply chain were identified: the business processes approach, the involvement of clients and suppliers in product design, and the modularization of products. In order to investigate the relations between the supply chain and product design, a case study of a link in the home appliance sector's supply chain was carried out. At the end, the implications of the research results were analyzed with the purpose of including the supply chain as another dimension of concurrent engineering in product design.
\end{abstract}

Keywords

Product design. Supply chain. PDP. SCM. 